\title{
A Comparative Study between Conventional and Bethesda System for Reporting Thyroid Cytopathology
}

\author{
Shabana Azad, Shaila N Shah and Rekha R Iyer \\ Department of Pathology, Govt. Medical College and Sir T Hospital, Bhavnagar-364001 Gujarat, India.
}

\section{ABSTRACT}

Background: Disorders of thyroid gland are very common. Thyroid cancers comprise $1 \%$ of all malignancies, and are the most common cancer of endocrine system. It is more common in females as compared to males.

Method: 51 Patients with enlarged thyroid gland were studied. All the thyroid FNAC cases were reported and compared by using both the conventional and the Bethesda System for Reporting Thyroid Cytopathology (TBSTRC). The conventional system includes description of the microscopic findings of the case along with a final impression at the end. In equivocal cases, the differentials were given. However, for statistical analysis, the reporting system was modified into five category system. The categories were-1) Inadequate 2) Benign 3) Equivocal 4) Follicular 5) Malignant

Results: The age at presentation of the patient varied widely from 10 years to 100 years. The mean age of presentation is 40 years. There was female preponderance amongst the patients ( $94.1 \%$ females). In the vast majority of the cases TBSRTC is equivalent to the conventional system in the pattern of reporting.

Conclusion: TBSRTC may be viewed as a better screening test for thyroid lesions. Follicular patterned lesions pose the greatest difficulty in evaluating thyroid FNAC smears with their being significant overlap in the cytological features of different lesions.

\section{Keywords: Thyroid Gland, FNAC, TBSRTC}

\section{Introduction}

Disorders of thyroid gland are very common. Iodine deficiency disorders and colloid goitre are endemic in some parts of India and is considered as a national health issue.

Thyroid cancers comprise $1 \%$ of all malignancies [1], and are the most common cancer of endocrine system. It is more common in females as compared to males ${ }^{[2]}$. The prognosis is good with mortality to incidence ratio of 0.23 worldwide, accounting for $0.4 \%$ of all cancer deaths. Most of the thyroid disorders, whether benign or malignant, present with enlarged thyroid gland. Thus apart from clinical examination and hormonal assay, fine needle aspiration cytology(FNAC) forms an integral part of work up for a patient with enlarged thyroid gland because it is safe, inexpensive and provides rapid results which helps in better patient selection for surgery. However, the interpretation of thyroid FNAC smears is not easy because of considerable similarity and overlaps between benign and malignant conditions especially the follicular patterned lesions. Moreover, follicular carcinoma cannot be diagnosed on cytology.

The Bethesda System for Reporting Thyroid Cytopathology (TBSRTC) was discussed and finalized in a conference in October $2007^{[3]}$.
TBSRTC classifies all the thyroid nodules into six general categories viz. Non Diagnostic/Unsatisfactory (ND); Benign(B); Atypia of Undetermined Significance/ Follicular Lesion of Undetermined Significance (AUS/ FLUS); Follicular Neoplasm/Suspicious of Follicular Neoplasm(FN); Suspicious of Malignancy(SM); Malignant(M).

As a recently introduced reporting system, it is necessary that it is studied at different centers to evaluate its utility, limitations and advantages, if any, over previous reporting schemes. We thus intend to study and compare the Bethesda system with the existing system of reporting at our centre.

\section{Materials and Methods}

51 Patients with enlarged thyroid gland were studied. All patients who were advised thyroid FNAC and willing to participate in the study were included.

Neck radiography, ultrasound, thyroid function tests, thyroid scan, any prior cytological/histological findings, any other relevant investigation were noted wherever available.

Following methods of sample acquisition were included:

1. FNAC smears.

2. Thyroidectomy Specimen 
Statistical Evaluation: The results are presented in frequencies, percentages and mean $\pm \mathrm{SD}$. Chi-square test was used to compare the categorical variables. The diagnostic accuracy of the test was calculated. The p-value $<0.05$ was considered significant. All the analysis was carried out on SPSS 16.0 version (Chicago, Inc., USA).

\section{Result}

FNAC evaluation of thyroid nodules reduces load of unnecessary surgeries for benign lesion and opens the way to timely surgical intervention when there is significant risk of malignancy.

Bethesda system for reporting thyroid cytopathology (BSRTC) streamlined the assessment and reporting of thyroid aspirates and alleviates the inter-observer variability of FNAC procedure.

\section{Discussion}

The study included 51 patients whose thyroid FNAC smears were evaluated. Majority of the patients were females. All the cases were reported using the conventional and Bethesda system. Benign category formed the largest category ( $60 \%$ cases).

Thus there is significant difference between our study and the metaanlytical study by Bongiovanni et $\mathrm{al}^{6}$. In the category wise distribution of the cases except for category 6 where the distribution is not significantly different $(p>0.05)$. Iodine deficiency disorders and colloid goitre are known to be endemic in India with a greater prevalence as compared to western countries ${ }^{7}$. This may have led to more proportion of cases being diagnosed as benign with consequent decrease in the other categories.

The advantage of Bethesda is that it states the risk of malignancy for each category. The further management of the patients also suggested after considering the malignancy risk.

Our category wise malignancy risk as compared to other studies is given below.

Table1: shows the distribution of patients according to age. About 1/3rd of patients were between 33-40 years (33.3\%) followed by $>50(29.4 \%),<30(23.5 \%)$ and $41-50(13.7 \%)$ years.

\begin{tabular}{|c|c|c|}
\hline Age in years & No. $(\mathbf{n}=\mathbf{5 1})$ & $\%$ \\
\hline$<30$ & 12 & 23.5 \\
\hline $30-40$ & 17 & 33.3 \\
\hline $41-50$ & 7 & 13.7 \\
\hline$>50$ & 15 & 29.4 \\
\hline Mean \pm SD (Range) & $39.98 \pm 16.23(10-72)$ & \\
\hline
\end{tabular}

Table 2: shows the distribution of patients according to gender. Majority of patients were females (94.1\%).

\begin{tabular}{|c|c|c|}
\hline Gender & No. $(\mathbf{n = 5 1 )}$ & $\%$ \\
\hline Male & 3 & 5.9 \\
\hline Female & 48 & 94.1 \\
\hline
\end{tabular}

Table 3: shows the comparison of conventional and TBSRTC methods. Benign was diagnosed in 35 patients by both conventional and TBSRTC methods. Malignancy was diagnosed in 3 patients by both conventional and TBSRTC methods.

\begin{tabular}{|c|c|c|c|c|c|c|c|}
\hline \multirow[b]{2}{*}{$\begin{array}{l}\text { Diagnosis on } \\
\text { conventional }\end{array}$} & \multicolumn{6}{|c|}{ Diagnosis on TBSRTC } & \multirow[b]{2}{*}{ Total } \\
\hline & $\begin{array}{c}\text { Non- } \\
\text { Diagnostic/ } \\
\text { Unsatisfactory }\end{array}$ & Benign & $\begin{array}{c}\text { Atypia of } \\
\text { undetermined } \\
\text { significance/ } \\
\text { Follicular lesion } \\
\text { of undetermined } \\
\text { significance }\end{array}$ & $\begin{array}{l}\text { Follicular } \\
\text { neoplasm/ } \\
\text { Suspicious } \\
\text { for follicular } \\
\text { neoplasm }\end{array}$ & $\begin{array}{l}\text { Suspicious } \\
\quad \text { for } \\
\text { Malignancy }\end{array}$ & Malignancy & \\
\hline Inadequate & 2 & 0 & 0 & 0 & 0 & 0 & 2 \\
\hline Benign & 4 & 35 & 1 & 1 & 0 & 0 & 41 \\
\hline Equivocal & 0 & 0 & 2 & 0 & 1 & 0 & 3 \\
\hline $\begin{array}{l}\text { Follicular } \\
\text { neoplasm }\end{array}$ & 0 & 0 & 0 & 1 & 0 & 0 & 1 \\
\hline Malignancy & 0 & 0 & 1 & 0 & 0 & 3 & 4 \\
\hline Total & 6 & 35 & 4 & 2 & 1 & 3 & 51 \\
\hline
\end{tabular}


Table 4; shows the comparison of diagnostic accuracy of conventional and TBSRTC method. The diagnostic accuracy of TBSRTC was $85.4 \%$ for benign and $75 \%$ for malignancy.

\begin{tabular}{|c|c|c|c|}
\hline & TBSRTC & Conventional & Diagnostic accuracy (\%) \\
\hline Benign & 35 & 41 & 85.4 \\
\hline Malignancy & 3 & 4 & 75.0 \\
\hline
\end{tabular}

Table 5: Malignancy rate for each category of TBSRTC

\begin{tabular}{|c|c|c|c|}
\hline Category (TBSRTC) & $\begin{array}{c}\% \text { of the total patient that } \\
\text { underwent surgery }\end{array}$ & Malignancy rate & NCI recommended rate \\
\hline Category 1 (ND) & $16.6 \%(1$ out of 6$)$ & $0(0 / 1)$ & $1-3 \%$ \\
\hline Category 2 (B) & $42.8 \%(15$ out of 35$)$ & $0(0 / 15)$ & $0-3 \%$ \\
\hline Category 3(AUS) & $50 \%(2$ out of 4$)$ & $50 \%(1 / 2)$ & $5-15 \%$ \\
\hline Category 4 (FN) & $25 \%(1$ out of 4$)$ & $0(0 / 1)$ & $15-30-\%$ \\
\hline Category 5(SM) & $50 \%(1$ out of 2$)$ & $100 \%(1 / 1)$ & $60-75 \%$ \\
\hline Category 6(M) & & & $97-99 \%$ \\
\hline
\end{tabular}

Table 6: Summary of few similar studies using TBSRTC showing category wise distribution of cases of all the FNAC.

\begin{tabular}{|c|c|c|c|c|c|}
\hline & Present study & Her-JuingWu & Theoharis $^{\mathbf{4}}$ & Bongiovanni $^{\mathbf{6}}$ & P value \\
\hline Cat1(ND) & $6(11.8 \%)$ & $278(20.1 \%)$ & $357(11.1 \%)$ & $3271(12.9 \%)$ & $<0.05$ \\
\hline Cat2(B) & $35(68.6 \%)$ & $539(39.0 \%)$ & $2368(73.8 \%)$ & $15104(59.3 \%)$ & $<0.05$ \\
\hline Cat3(AUS) & $4(7.8 \%)$ & $376(27.2 \%)$ & $95(3.0 \%)$ & $2441(9.6 \%)$ & $<0.05$ \\
\hline Cat4(FN) & $2(3.9 \%)$ & $116(8.4 \%)$ & $176(5.5 \%)$ & $2571(10.1 \%)$ & $<0.05$ \\
\hline Cat5(SM) & $1(2 \%)$ & $36(2.6 \%)$ & $43(1.4 \%)$ & $680(2.7 \%)$ & $<0.05$ \\
\hline Cat6(M) & $3(5.9 \%)$ & $37(2.7 \%)$ & $168(5.2 \%)$ & $1378(5.4 \%)$ & $>0.05$ \\
\hline Total FNACs & $\mathbf{5 1 ( 1 0 0 \% )}$ & $\mathbf{1 3 8 2 ( 1 0 0 \% )}$ & $\mathbf{3 2 0 7}(\mathbf{1 0 0} \%)$ & $\mathbf{2 5 , 4 4 5 ( 1 0 0 \% )}$ & \\
\hline
\end{tabular}

\begin{tabular}{|c|c|c|c|c|c|}
\hline & Present study & VY Jo et al & Her-Juing $\mathbf{W u}^{\mathbf{4}}$ & Theoris $^{5}$ & Bongiovanni $^{\mathbf{6}}$ \\
\hline Cat1(ND) & Nil & $8.9 \%$ & $14 \%$ & Not calculated $^{2}$ & $16.8 \%$ \\
\hline Cat2(B) & Nil & $1.1 \%$ & $9.5 \%$ & $9.8 \%$ & $3.7 \%$ \\
\hline Cat3(AUS) & $50 \%$ & $17 \%$ & $22 \%$ & $48 \%$ & $15.9 \%$ \\
\hline Cat4(FN) & Nil & $25.5 \%$ & $27 \%$ & $34 \%$ & $26.1 \%$ \\
\hline Cat5(SM) & $100 \%$ & $70 \%$ & $67 \%$ & $87 \%$ & $75.2 \%$ \\
\hline Cat6(M) & & $98.1 \%$ & $100 \%$ & $100 \%$ & $98.6 \%$ \\
\hline
\end{tabular}

In the present study, the malignancy rate is not significant due to very less sample size and poor histological follow up.

Category I-Nondiagnostic or Unsatisfactory (ND/ UNS) An UNS specimen is always ND but some technically satisfactory specimens may also be considered. In our present study ND/UNS cases were $6(11.8 \%)$ as compared to $2(3.9 \%)$ patients in the corresponding category by conventional system. The difference observed in the number of cases in the category 1 and 2 of the two systems, may be due to well defined and hence reproducible criteria of adequacy in TBSRTC as opposed to subjective criteria in the conventional system. Among the cases with histological follow up, we had 1 FNA smear reported as inadequate. The smear showed only cyst fluid with macrophages only. The case was benign on histological follow up. In our study, though malignancy rate is 0 , the sample size is too small for it to be significant.

Category II-Benign This category includes benign follicular nodule (adenomatoid nodule, colloid nodule), lymphocytic (Hashimotos) thyroiditis and granulomatous (subacute) thyroiditis. Most of our cases were from this category with a total of $35(68.6 \%)$ cases . There is significantly large proportion of cases in this category in our study as compared to Bongiovanni with epidemiology of iodine deficiency disorders being the probable cause. 
Among the cases with histological follow up, benign diagnosis was rendered in 15 out of 35 FNAC. Histologically all were benign.

Sampling errors are the important source of errors especially at centers where the entire thyroid FNAC are palpation guided.

The recommended management of this category is clinical follow up.

Category III-Atypia of Undetermined Significance or Follicular Lesion of Undetermined Significance (AUS/ FLUS) Thyroid FNAs that do not fit into benign, suspicious or malignant categories are included here. AUS/FLUS is reserved for specimens that contain cells (follicular, lymphoid) with architectural atypia that isn't sufficient to be classified as suspicious for a follicular neoplasm (FN) or malignancy and on the other hand atypia is more marked than benign change .

Though some guidelines are mentioned, the use of this category is varied widely from $3 \%$ of all the cases by Theoharis et al ${ }^{[5]}$ to $27.2 \%$ by Her Juing Wu et al ${ }^{[4]}$. The average usage of this term in the metaanalytical study by Bongiovanni et al ${ }^{[6]}$ is $9.6 \%$. In our study it has been used in $7.8 \%$ of cases. It is close to the recommended $7 \%$ limit for this category by TBSRTC. This limit has been recommended to avoid indiscriminate use of this category.

Of the 2 cases with histological follow up 1 was benign neoplastic hurthle cell.

The suggested management i.e follow up with repeat FNAC is also being evaluated.

Category IV-FN or Suspicious for a FN (FN/SFN) The aim of this category is to identify a nodule that might be a follicular carcinoma. Follicular carcinomas have cytomorphologic features that distinguish them from benign follicular nodules but do not permit distinction from a FA, none of the cytological criteria or markers have found to be reproducible and of diagnostic value ${ }^{[9]}$. The role of thyroid FNAC is to separate neoplastic from non neoplastic lesions. In our opinion, the role of cytology is to detect neoplastic process or rather to select cases with a great livelihood of having carcinoma. Since every adenoma on cytology may turn out to be carcinoma, it may be said that every follicular adenoma missed on cytology is like missing a potential follicular carcinoma.

Of the $1 \mathrm{FN}$ diagnosis given by us with histopathological correlation was FA. The malignancy rate as published by TBSRTC is $15-30 \%$.

TBSRTC recommends lobectomy for this category.
Category V-Suspicious for Malignancy The use of this category conveys a strong suspicion for malignancy in the absence of sufficient definitive evidence for malignancy. 1 patient had histological follow up. The cytological suspicion correlate with the histological diagnosis thus yielding a malignancy rate of $100 \%$.

The aim of segregating 'suspicious' category apart from 'malignant' category is to preserve the very high predictive value of the malignant category without compromising the overall sensitivity of the procedure ${ }^{[10]}$. The use of this category is slightly lower (2\%) in our setup. Though the malignancy rate is $100 \%$, however, it should be noted that statistical analysis of this category is not significant due to very small number of cases.

TBSRTC recommends near-total thyroidectomy or surgical lobectomy for cases in this category.

Category VI-Malignant The general category malignant is used whenever the cytomorphologic features are conclusive for malignancy.

TBSRTC recommends near-total thyroidectomy for these cases of malignancy.

To summarize, we feel that on statistical basis there is not much difference between the conventional and TBSRTC. However, TBSRTC offers advantage of being more reproducible and more management oriented. But, the category 3 is heterogeneous and its usage still has large influence of subjectivity. Thus, larger studies are needed to refine the criteria for this surgery.

The cytology can at best be one of the investigative tool for assessing thyroid nodules. In cases with equivocal results on cytology, we feel that using TBSRTC recommended management may not be appropriate for all patients and that the treatment plan should be individualized taking into consideration all the other investigations, clinical profile and patients' wish.

\section{Conclusion}

The mean age of presentation is 40 years with female preponderance amongst the patients. In the vast majority of the cases TBSRTC is equivalent to the conventional system in the pattern of reporting. TBSRTC may be used for reporting thyroid FNAC smears as it brings about an objectivity. For, benign category (cat2) we suggest that presence of sufficient number of singly scattered benign follicular cells should also be considered adequate despite absence of cell clusters. The category AUS (cat3) is heterogeneous category with considerable overlap with category FN/SFN (cat4) and category benign (cat2) because of the imprecise criteria. Despite being objective, 
there is always some degree of unavoidable subjectivity in thyroid cytopathology. Hence we recommend that larger centres should calculate their own malignancy rates and should be communicated to the treating surgeons for better interpretation of the results. The management of the patient should be based on the malignancy rate for the centre along with clinical and radiological correlation rather than following the TBSRTC guidelines for all the patients.

\section{Refereces}

1. DeLellis RA, Lloyd RV, Heitz PU, Eng C editors: WHO classification of Tumors: Pathology and genetics of tumors of endocrine organa. Lyon: International agency for research of cancer. IARC press 2004.

2. Layfield LJ, Morton MJ, Cramer HM, Hirschowitz S. Implications of the proposed thyroid fine-needle aspiration category of "follicular lesion of undetermined significance": A five-year multi-institutional analysis. Diagn Cytopathol. 2009 Oct;37(10):710-4.

3. Cibas ES, Ali SZ. The Bethesda system for reporting thyroid cytopathology. Am J Clin Pathol. 2009;132:658-665

4. Wu HH, Rose C, Elsheikh TM. The Bethesda system for reporting thyroid cytopathology: An experience of 1,382 cases in a community practice setting with the implication for risk of neoplasm and risk of malignancy. Diagn Cytopathol. 2012 May;40(5):399-403.
5. Theoharis CG, Schofield KM, Hammers L, Udelsman $\mathrm{R}$, Chhieng DC. The Bethesda thyroid fine-needle aspiration classification system: year 1 at an academic institution. Thyroid. 2009 Nov;19(11):1215-23.

6. Bongiovanni M, Spitale A, Faquin WC, Mazzucchelli L, Baloch ZW. The Bethesda System for Reporting Thyroid Cytopathology: a meta-analysis. Acta Cytol. 2012;56(4):3339. doi: 10.1159/000339959.

7. AliSZ, Cibas ES. The Bethesda System for Reporting Thyroid Cytopathology: definitions, criteria and Explnanatory Notes. New York: Springer; 2010

8. Jo VY, Stelow EB, Dustin SM, Hanley KZ. Malignancy risk for fine-needle aspiration of thyroid lesions according to the Bethesda System for Reporting Thyroid Cytopathology. Am J Clin Pathol. 2010 Sep;134(3):450-6.

9. Baloch ZW, Fleisher S, LiVolsi VA, Gupta PK. Diagnosis of "follicular neoplasm": a gray zone in thyroid fine-needle aspiration cytology. Diagn Cytopathol. 2002 Jan;26(1):41-4.

10. Baloch ZW, LiVolsi VA, Asa SL, Rosai J, Merino MJ, Randolph G, Vielh P, DeMay RM, Sidawy MK, Frable WJ. Diagnostic terminology and morphologic criteria for cytologic diagnosis of thyroid lesions: a synopsis of the National Cancer Institute Thyroid Fine-Needle Aspiration State of the Science Conference. Diagn Cytopathol. 2008 Jun;36(6):425-37. doi: 10.1002/dc.20830.

*Corresponding author:

Dr. Shaila N Shah, 11, Kalpdroom Flats, Near Takhteshwar Post Office, Waghawadi Road, Bhavnagar-364001, Gujarat, India

Phone: +91 9824561875

Email: shaila.shah15@yahoo.com

Financial or other Competing Interests: None. 